\title{
Dielectric Properties of Natural Ester, Synthetic Ester Midel 7131 and Mineral Oil Diala D
}

\author{
Yi Jing, Igor V. Timoshkin, Mark P. Wilson, Martin J. Given, Scott J. MacGregor, Tao Wang \\ Department of Electronic and Electrical Engineering \\ University of Strathclyde, 204 George Street, Glasgow, G1 1XW, UK
}

and Jane M. Lehr

Sandia National Laboratories, PO Box 5800, MS 1193, Albuquerque, NM 87185-1193, USA

\begin{abstract}
The insulating liquids used in industrial applications are typically mineral oils. In recent years however, significant attention has been paid to alternative insulating fluids, including synthetic and natural ester liquids. In order to expand their practical applications, it is important to have detailed information on their dielectric properties. In this present paper, the dielectric properties of synthetic ester, Midel 7131; mineral oil, Shell Diala D; and vegetable (rapeseed) oil have been investigated. It has been shown that Midel 7131 has a higher ac breakdown voltage $(27.6 \mathrm{kV})$ as compared with Diala D oil $(26.4 \mathrm{kV})$ and rapeseed oil $(24.6 \mathrm{kV})$. However, the breakdown voltage of the Diala D oil has the smallest standard deviation (7\%) amongst the tested liquids (13\% for Midel 7131 and $11 \%$ for rapeseed oil). Statistical analysis of the breakdown voltages has been conducted and it has been shown that the ac breakdown voltages can be described by a normal distribution. dc $I-V$ characteristics have been measured and the space charge saturation regime has been observed for all three liquids starting from $\sim 9 \mathrm{kV}$ for positive energisation and $\sim 10 \mathrm{kV}$ for negative energisation in the point-plane topology. Apparent mobilities of the charge carriers in the tested liquids have been obtained using $I^{1 / 2}-V$ curves; these mobilities can be used for calculation of the space charge influenced distribution of the electric field in liquid insulators stressed with dc voltage. Such analysis can be important for design and exploitation of HVDC power systems.
\end{abstract}

Index terms - Liquid dielectrics, breakdown, conduction.

\section{INTRODUCTION}

DIELECTRIC liquids are used to provide insulation protection in high-voltage (HV) systems. These liquids also facilitate thermal stability of HV equipment due to their thermo-conduction properties. The insulating liquids typically employed in power systems are naphthenic mineral oils. However, stringent environmental protection regulations encourage operators and manufacturers of HV equipment to use bio-degradable liquids with low toxicity. Reduction of the footprint of modern high-voltage and pulsed-power equipment results in demand for insulating liquids with improved dielectric properties, due to the resultant higher levels of electrical stress. In response to this demand, manufacturers of dielectric liquids are actively investing in the development of new products, such as natural and synthetic esters, for applications in the power and pulsed-power industries.

Natural, organic oils and synthetic esters are considered as potential substitutes for traditional naphthenic mineral oils. However, their dielectric properties are not yet fully known, especially in the case of dc energisation. Recent advances and investments in HVDC systems require detailed information about the dielectric behavior of insulating fluids under ac and dc electric stresses [1]. HVDC techniques are suitable for transmission of electrical power over long distances, and with the development of renewable sources this approach has attracted the attention of the power industry for transmission of electrical power generated by offshore wind farms. In HVDC systems, for example in HVDC convertor transformers, the insulation is stressed with both ac and dc voltages. Therefore, it is important to investigate the dielectric properties of insulating liquids, and to understand their behavior under both types of energisation. As indicated in a report by National Grid [1], "DC transformers cost in the region of $£ 5 \mathrm{M}$ per phase and failures have significant outage cost". Also, it is known that the HVDC transformer failure rate exceeds the failure rate of conventional transmissionbased units by 5-10 times [1]. 
Under ac conditions the field distribution is dominated by the permittivity of the dielectric and the conductivity is regarded as only being significant in its contribution to losses in the system. However, the formation of bubbles as a result of Joule heating which is dependent on the conductivity has been proposed as a mechanism for liquid breakdown [2]. In addition, under dc conditions, it has been shown in solid insulation systems that conductivity and the resulting space charge distribution dominates the field distribution rather than the permittivity [3]. For a liquid, due to the higher mobilities of charge carriers, it is likely that the effect of space charge distributions will be more significant. The presence of this space charge implies that field calculations based on solutions to the Laplace equation will be inadequate and approaches based on the Poisson and current continuity equations are required [4]. To perform such analyses of the field distributions, information on the effective mobility of the charge carriers in the liquids is required. At present, measurement of the dc conductivity of oil is not routine, [1], and it is not possible to derive effective mobilities for the charge carriers from the data sheets provided by manufacturers. Information on the dc dielectric behavior of insulating liquids will potentially influence design of HVDC systems and will help to manage these liquids.

This paper reports experimental data on the dielectric characteristics of three insulating liquids: Diala D; a synthetic ester fluid, Midel 7131 and a food-grade rapeseed oil. The ac breakdown voltage of the dielectric fluids has been measured using a test cell manufactured according to the ASTM D181604 standard and the mean breakdown voltage has been calculated. Statistical analysis using the Microsoft Office Excel 2003 and OriginPro v.8.6 software packages has shown that the data is normally distributed allowing calculation of the standard deviation of the breakdown voltage and this has been used to estimate the 1, 10, 50 and $90 \%$ breakdown probability for each liquid. This data is relevant to the design of power and pulse power equipment, [5-11], as it affects safety-margin design requirements for liquid-insulated, high-voltage equipment. Values of the effective mobility of the charge carriers in the liquids were obtained from pre-breakdown $I-V$ characteristics, measured in a point-plane electrode topology, following the procedure reported in [12].

\section{AC BREAKDOWN VOLTAGE TESTS}

\subsection{EXPERIMENTAL ARRANGEMENT}

$A C$ breakdown voltages of the liquids under investigation were measured in an electrode configuration which satisfies the ASTM D1816-04 standard, [13]. The tests were conducted at atmospheric pressure and room temperature. From the data presented in [14] the expected increase in the breakdown strength of mineral oil is $\sim 5 \%$ when the ambient pressure is increased from 0 to $1 \mathrm{~atm}$. It is known that temperature affects the conduction and breakdown properties of the insulating liquids, $[15,16]$. However, a change in temperature of $20^{\circ} \mathrm{C}$ to $80^{\circ} \mathrm{C}$ only resulted in a $\sim 7 \%$ decrease in the ac breakdown voltage for mineral oil, [17]. From data in [18] changes of $\pm 5^{\circ} \mathrm{C}$ about a temperature of $20{ }^{\circ} \mathrm{C}$ leads to a $\sim 5 \%$ change in measured conductivity. Therefore, it is assumed that the small shifts in ambient temperature and pressure that occurred in the course of the measurements will have had negligible effects on the results obtained.

The oil samples were used "as received" with no pretreatment before measurements. It is known that contaminants and moisture in dielectric fluids affect their breakdown properties, [15]. For example, a $\sim 34 \%$ decrease in the ac breakdown strength for mineral oil with $43 \%$ relative humidity as compared with dry oil has been reported in [19]. Many different pretreatment protocols have been described in the literature aimed at reducing moisture, dissolved gases and contaminants from liquid samples: samples have been degassed and dried but not filtered, [11]; filtered using a relatively large filter $(10-16 \mu \mathrm{m})$ but not degassed or dried, [20], or only filtered using a $5 \mu \mathrm{m}$ filter, [21]. The results of dielectric studies in which "as received" insulating fluids were used without any additional filtration, de-gassing or dehumidification are reported in the literature, [22, 23]. In the work reported on aged biodegradable oils, [24], no details of pre-treatment of the liquids prior to or post-ageing is reported. Given this wide range of possible pre-treatments the authors felt that using the oils as received provided the starting point for assessing the relative properties of the three liquids. This approach has the advantage that the obtained results help to understand the dielectric behavior of commercially-available insulating liquids used in practical engineering applications without additional processing. The results obtained in the present paper are compared with the studies in which pretreated dielectric liquids have been used.

Figure 1 show the electrode topology used in the present tests. A pair of spherically-capped, polished, brass electrodes was incorporated into a ceramic container; the electrode profile is shown in Figure 1. The gap between the two electrodes is $0.5 \mathrm{~mm}$. AC breakdown voltages were measured using a Tektronix TDS220 digital storage oscilloscope and a Tektronix P6015A HV probe.

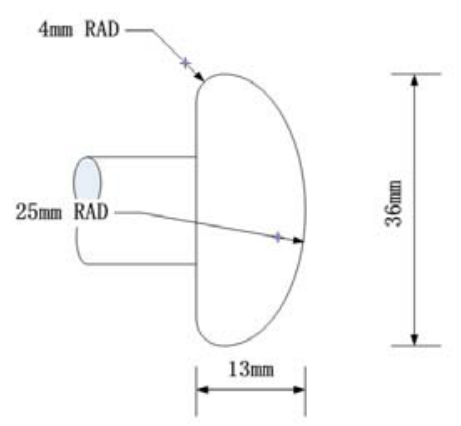

Figure 1. Cross section of spherically-capped electrode.

A Foster breakdown test apparatus was used as the power source. This apparatus produces a $50 \mathrm{~Hz}$ ac voltage across the test cell, filled with the liquid under test. AC voltage was applied across the electrodes of the test cell with a rate-of-rise 
of $1 \mathrm{kV} / \mathrm{s} .70$ breakdown events were registered for each liquid sample. Average breakdown voltages were calculated using breakdown data obtained in three independent tests (fresh samples were used for each test) for each type of liquid. The samples were kept under vacuum for 1.5 hours at room temperature to remove gas bubbles introduced into the liquid samples during pouring procedure. The electrodes were polished after each series of tests to remove damage produced by breakdowns, and the test cell and electrodes were cleaned with alcohol and then washed with distilled water. The test cell and electrodes were then dried in an oven for 2 hours with $40^{\circ} \mathrm{C}$ to remove water prior to the next test.

The relative water content of the liquids used in the present study has been examined using "Omniport 20" moisture in oil probe $(\mathrm{E}+\mathrm{E}$ Electronik $\mathrm{GmbH})$. This can be converted into an absolute water content using the linear relationship between these two values, [25]. The water solubility values for Diala D ( 77 ppm), Midel $7131 \quad(\sim 2600 \mathrm{ppm})$ and rapeseed $(\sim 772 \mathrm{ppm})$ oils required for this analysis have been taken from papers [26, 27], and [28], respectively. The evaluated absolute water content for Diala D is $\sim 39$ ppm, Midel 7131 is $\sim 1352 \mathrm{ppm}$ and for rapeseed oils is $\sim 417 \mathrm{ppm}$. These values are not exact and given here for evaluation purpose only, such high values of the absolute water content can be explained by the fact that the liquid samples were kept in ambient laboratory conditions, [19].

\subsection{EXPERIMENTAL RESULTS}

Figure 2 shows ac breakdown voltages for Midel 7131 synthetic ester fluid, Diala D mineral oil and rape-seed oil. Each point in this graph shows the average breakdown voltage of three individual tests. This figure shows that the breakdown voltages for all three liquids display considerable spread. Potential conditioning in the breakdown behavior of liquids (slightly lower breakdown voltages for shots 5-20) may be observed in Figure 2, however this conditioning is not well pronounced. Therefore, statistical analysis of breakdown data was conducted using the full data set of 70 data points.

Figure 2 shows a dependence of the breakdown voltage, $V_{b r}$, of the three tested fluids on the breakdown number, $N$, which demonstrates a slight increase in $V_{b r}$ with $N$. This tendency has also been noted in [29] and in [11] for mineral oil and natural ester liquid, and can potentially be explained by removal of gas bubbles and impurities in the liquid and "conditioning" of the electrodes (removal of sharp micro-asperities on the electrode's surface) by spark discharges. The inter-electrode gap in the ac breakdown study reported in [11] was $1 \mathrm{~mm}$. The authors of [20] observed that the breakdown voltage values "are scattered around a mean value" and noted that in their tests the higher values of the ac breakdown voltage were usually observed at the beginning of the breakdown tests. The inter-electrode gap used in [20] was $2.5 \mathrm{~mm}$. No noticeable conditioning can be observed in the breakdown series for mineral oils and ester fluids presented in paper [20]. However, in [30] the authors reported a pronounced increase in the ac breakdown voltage for the mineral oil which stabilizes after $\sim 10$ breakdown events. The electrode conditioning effect is discussed in [15], where it is shown that the breakdown strength of degassed $n$-hexane in a sub-mm gap increases significantly during the first 50 breakdown events (from 300 to $750 \mathrm{kV} / \mathrm{cm}$ ), then decreases and stabilizes.

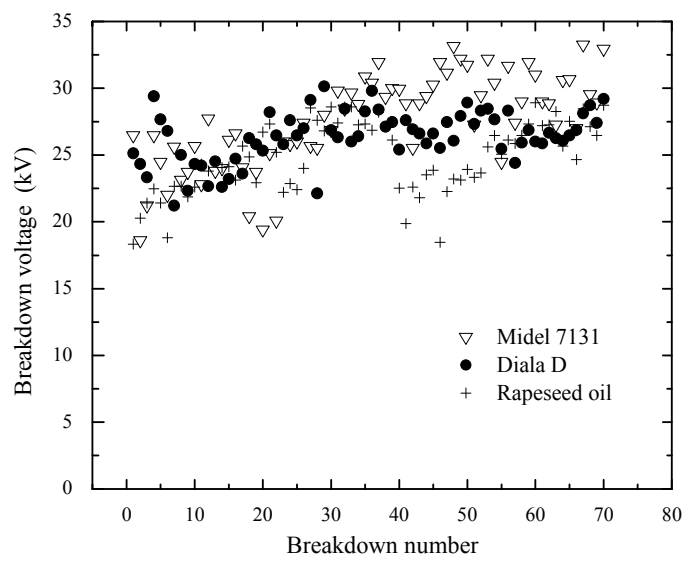

Figure 2. Distribution of breakdown voltage of tested liquids.

Figure 3 shows frequency histograms of breakdown voltages for each of the tested liquids.
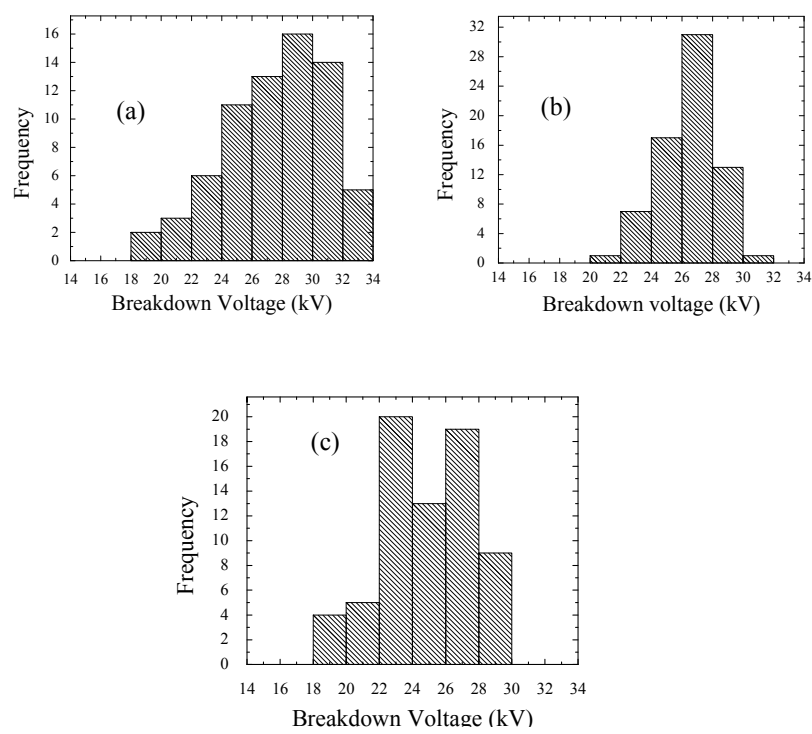

Figure 3. Histogram of average breakdown voltage for Midel 7131, (a); Diala S3, (b); and rapeseed oil; (c).

The breakdown voltage values of Diala $\mathrm{D}$ concentrate in the region of $25-29 \mathrm{kV}$, indicating a relatively narrow variation in breakdown voltage. The breakdown voltages for Midel 7131 are mostly concentrated in the region of $23-33 \mathrm{kV}$; this spread in the breakdown voltages is larger than that for Diala D oil. The majority of the breakdown voltages for the rapeseed oil are located in the region of 21-29 $\mathrm{kV}$. The results of the statistical analysis of the breakdown voltage data for these 
liquids (average breakdown voltage and standard deviation) are shown in Table 1.

As can be seen from Table 1, Midel 7131 has the highest average ac breakdown voltage, $27.6 \mathrm{kV}$, however the standard deviation is also high, $3.5 \mathrm{kV}$. Diala $\mathrm{D}$ demonstrated the minimum standard deviation, $1.9 \mathrm{kV}$ with an average breakdown voltage of $26.4 \mathrm{kV}$.

Table 1. The mean breakdown voltage and its standard deviation.

\begin{tabular}{c|c|c}
\hline & $\begin{array}{c}\text { Mean } \\
(\mathrm{kV})\end{array}$ & $\begin{array}{c}\text { Standard deviation }(\mathrm{kV} \\
\text { and \%) }\end{array}$ \\
\hline Midel 7131 & 27.6 & $3.5(13 \%)$ \\
\hline Diala D & 26.4 & $1.9(7 \%)$ \\
\hline Rapeseed oil & 24.8 & $2.7(11 \%)$ \\
\hline
\end{tabular}

The rapeseed oil has the lowest average breakdown voltage, $24.8 \mathrm{kV}(\sim 6 \%$ lower than that of Diala D), however its standard deviation value $(11 \%)$ is between those for Midel $7131(13 \%)$ and Diala D (7\%). These values are close to the standard deviation values obtained in [11] for mineral oil (Nytro 10 GB, 9.5\%), synthetic ester (Midel 7131, 13\%) and natural ester (FR3, 13\%). The liquids used in [11] were cleaned (filtered, de-hydrated and de-gassed) before the tests. These data show that the insulating liquids "as received" have similar spread in their breakdown voltages as compared with the cleaned insulating liquids, and the ac breakdown voltages of the food-grade rapeseed oil are close to the ac breakdown voltages of the commercially-available insulating liquids. Therefore, such natural ester fluids can potentially be used in some practical applications which require an inexpensive, environmentally-friendly liquid dielectric, with good breakdown stability.

Although the particle content in the tested fluids have not been examined, it is interesting to note that impurities in dielectric liquids can not only decrease, but in some cases increase their dielectric strength. For example, paper [31] reported on the ac and impulsive breakdown voltages of the pure, commercially available transformer oil, Univolt-60 (oil A), and the same oil doped with $0.3 \%$ anthracene (oil B). This paper shows that the dielectric strength of oil $\mathrm{B}$ can be higher or lower than that of oil A, depending on the inter-electrode distance and the field non-uniformity factor (the ratio between the maximum and average fields in the gap). The authors concluded that anthracene "inhibits the $60 \mathrm{~Hz}$ breakdown initiation process in quasi-uniform fields" and "increases ability of streamers to propagate across the gap" in the case of highly divergent electric fields, [31]. An apparent increase in the dielectric breakdown strength of the insulating oils seeded with magnetite nano-particles particles has been reported in number of papers, [32-34]. However, the detailed discussion of this interesting effect and its potential practical applications is beyond the scope of the present paper.

The statistical analysis of the ac breakdown results ( 70 average breakdown voltages for each liquid) performed in the present paper is based the normal distribution. It has been shown that this type of distribution can be used in the analysis of the ac breakdown voltages of mineral oils, natural and synthetic esters, $[11,20]$. If the data are distributed normally, the standard deviations for each of these three liquids can be established. Reliable standard deviation in breakdown voltage is important for comparison of the dielectric performance of insulating liquids; it is desirable to use a liquid with minimum spread in its breakdown voltage. This will provide a higher degree of predictability in the dielectric performance, which can affect the design and maintenance of the high-voltage systems. The mean and standard deviation values obtained for the normally-distributed breakdown voltages can be used in the design of power systems for prediction of the dielectric performance of insulating liquids. The mean voltage, $U_{50 \%}$ and the withstand voltage, $U_{1 \%}$ are used in the insulation design of high-voltage equipment, [30, 35].

In order to determine the distribution of the breakdown voltage for each liquid, the Kolmogorov-Smirnov test of normality was used and $p$-values were calculated (the significance level was set to 0.05 ). If the $p$-value is higher than this level, the hypothesis that the breakdown voltage values can be described by the normal distribution is accepted. Table 2 shows the results of the normality test. As can be seen from Table 2, all three populations of the breakdown voltages for Midel 7131, Diala D and rapeseed oil potentially belong to the normal distribution.

Table 2. Hypothesis test results of three tested samples.

\begin{tabular}{c|c|c}
\hline & $p-$ value & $\begin{array}{c}\text { Conformity to normal } \\
\text { distribution }\end{array}$ \\
\hline Midel 7131 & 0.32035 & Accepted \\
\hline Diala D & 0.10015 & Accepted \\
\hline Rapeseed oil & 0.10468 & Accepted \\
\hline
\end{tabular}

Figures 4-6 show cumulative probability plots of the breakdown voltages of these liquids, and the data predicted by the normal distribution (solid reference lines). These figure show that the experimental breakdown data (open circles) deviate from the predicted cumulative distribution functions (solid straight lines in these figures) for probabilities below $\sim 10 \%$ and above $\sim 90 \%$. The experimental data show that the actual breakdown voltage is lower than the voltage predicted by the cumulative normal distribution. This information can be important for manufacturers of power systems, and should be taken into account in the design of such systems.

The predicted breakdown voltages with probabilities of $1 \%$, $10 \%, 50 \%$ and $90 \%, V_{1 \%}, V_{10 \%}, V_{50 \%}$ and $V_{90 \%}$, have been calculated assuming that the data are distributed normally, and these voltage are given in Table 3. $V_{1 \%}, V_{10 \%}, V_{50 \%}$ and $V_{90 \%}$ voltages can be compared with the actual breakdown voltages in order to evaluate the risk levels associated with insulation design based on statistical analysis.

Table 3. $V_{1 \%}, V_{10 \%}, V_{50 \%} V_{90 \%}$ values for the tested liquids.

\begin{tabular}{c|c|c|c|c}
\hline & $V_{1 \%}$ & $V_{10 \%}$ & $V_{50 \%}$ & $V_{90 \%}$ \\
\hline Midel 7131 & 18.6 & 22.9 & 28.9 & 31.9 \\
\hline Diala D & 21.2 & 23.5 & 26.5 & 28.7 \\
\hline Rapeseed oil & 18.3 & 21.6 & 24.8 & 28.5 \\
\hline
\end{tabular}




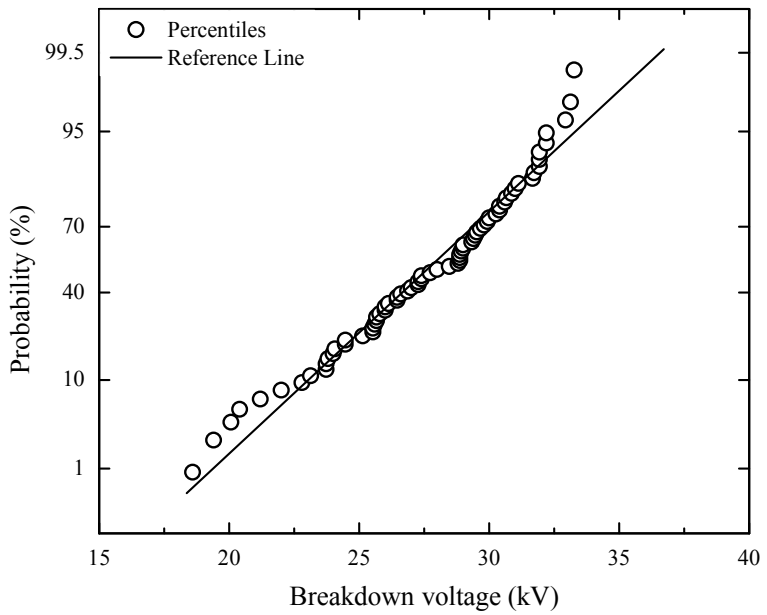

Figure 4. Normal probability plot of Midel 7131.

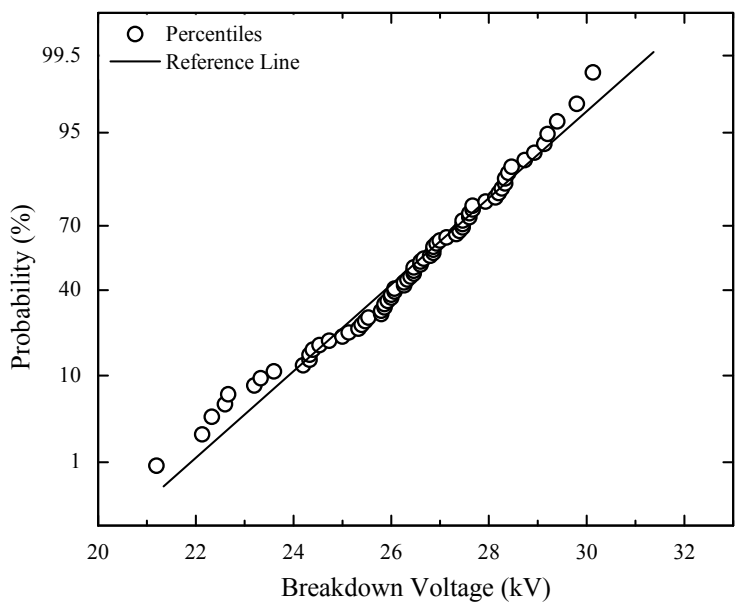

Figure 5. Normal probability plot of Diala D.

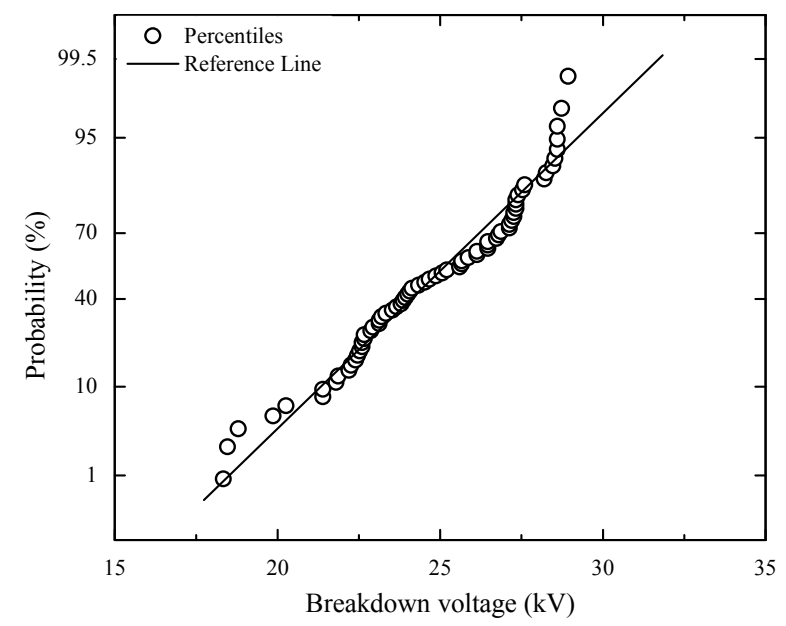

Figure 6. Normal probability plot of rapeseed oil.

\section{DC PRE-BREAKDOWN CURRENT}

\subsection{EXPERIMENTAL ARRANGEMENT}

As it was discussed in the Introduction, the dc conductivity is important parameter which can influence design of the HVDC systems and management of the insulating liquids stressed with dc voltage. Also, the mobility of charge carriers in the insulating fluids will affect the electric field distribution in the high voltage equipment. In the present work, $I-V$ curves were obtained for Midel 7131, Diala D and rapeseed oil in a point-plane electrode topology. The mobility of the charge carriers has been obtained and $\sqrt{ } I(V)$ curves are used for identification of different conductivity regimes which will influence the space charge distribution between the electrodes. The gap between the electrodes was $5 \mathrm{~mm}$, and the radius of the needle tip was $\sim 14 \mu \mathrm{m}$. Both positive and negative dc voltages were applied to the point electrode. The conduction current in the oil samples was measured using a custom-built, current-sensing amplifier, with a $1 \mathrm{k} \Omega$ current-viewing resistor. The voltage output from the amplifier was monitored using a Tektronix TDS2024 digital storage oscilloscope, and the applied voltage was monitored using a TESTEC HVP-40 HV probe.

\subsection{TEST PROTOCOL}

The point-plane electrode topology described in Section 3.1 was stressed with dc voltage; the voltage was increased from 0 to the maximum value that could be applied without inducing breakdown (positive: $+18 \mathrm{kV}$; negative: $-30 \mathrm{kV}$ ) in $1 \mathrm{kV}$ steps. The conduction current values were recorded for each voltage step. Three independent current tests were conducted per fluid, using a fresh liquid sample for each test. As in the case of ac breakdown tests, the test cell and electrodes were cleaned with alcohol, washed with distilled water, and dried in an oven after each set of three measurements.

\subsection{RESULTS: MOBILITY OF CHARGE CARRIERS}

Figures 7-8 show the square root of the conduction current for all three liquids for negative and positive energisation. The results show that at low voltages the square root of current behaves non-linearly; however with an increase in voltage $\sqrt{ } I(V)$ becomes a linear function, [36]. This linear behavior indicates the space-charge saturation regime. The constant apparent mobility of the charge carriers, $\mu$, can be calculated using the $\sqrt{ } I(V)$ curve. The basis of this calculation method has been described in [36]. The straight lines in Figures 7-8 were added to indicate the space charge saturation range. In the region where the square root of current has a linear relation with the applied voltage, the mobility, $\mu$, can be calculated using the following equations:

$y=B x+A, \quad$ where $y=\sqrt{I}(n A), x=V(k V)$ 


$$
\begin{aligned}
B & =\sqrt{\frac{2 \mu \varepsilon_{o} \varepsilon_{l}}{d}}\left[\frac{n A^{1 / 2}}{k V}\right], \quad A=\sqrt{\frac{2 \mu \varepsilon_{o} \varepsilon_{l}}{d}} V_{o}\left[n A^{1 / 2}\right] \\
\mu & =\frac{B^{2} 10^{-15} d}{2 \varepsilon_{o} \varepsilon_{l}}\left[\mathrm{~cm}^{2} V^{-1} \mathrm{~s}^{-1}\right]
\end{aligned}
$$

where $I$ is current, $V$ is applied voltage, $\varepsilon_{0}$ is permittivity of free space, and $\varepsilon_{l}$ is relative permittivity of the insulating liquid, $d$ in the gap distance between the point high voltage electrode and the grounded plane electrode.

The relative permittivities of the liquids are required in order to calculate the mobility, these values have been taken from [37] and they are: $\varepsilon_{l}=2.5$ for rapeseed oil; $\varepsilon_{l}=2.8$ for Diala D oil; $\varepsilon_{l}=3.2$ for Midel 7131 liquid. The coefficient $B$ and mobility, $\mu$, for each liquid are given in Table 4 .

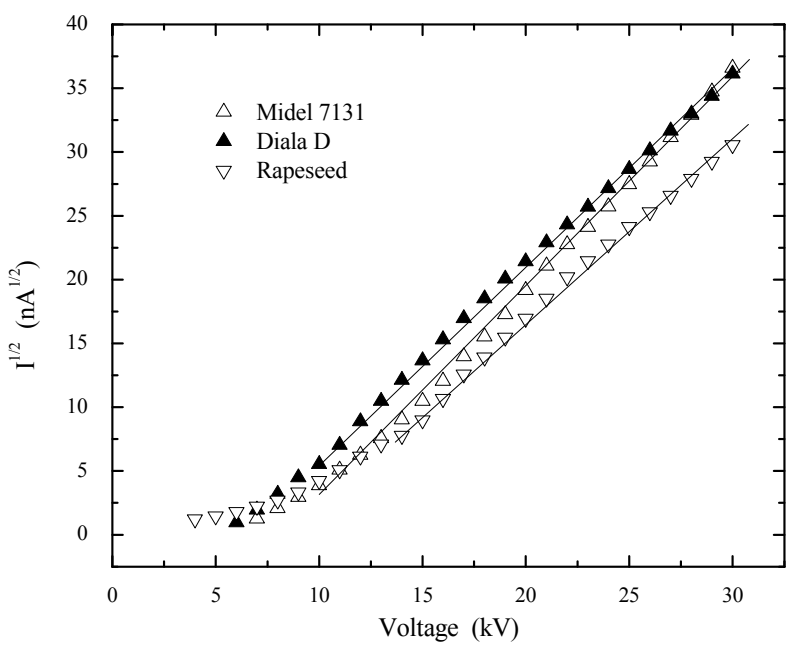

Figure 7. $\sqrt{ } I(V)$ plot of three oils, negative energisation. $\mathrm{R}^{2}$ coefficients: 0.9990 for Midel $7131 ; 0.9996$ for Diala D; 0.9988 for rapeseed oil.

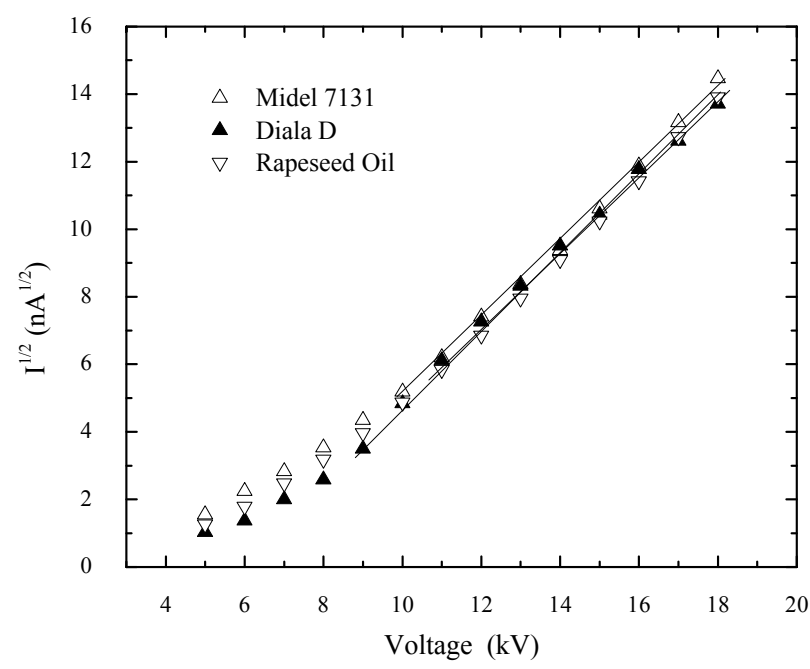

Figure 8. $\sqrt{ } I(V)$ plot of three oils, positive energisation. $R^{2}$ coefficients: 0.9987 for Midel 7131; 0.9991 for Diala D; 0.9995 for rapeseed oil.
The calculation results show that the apparent mobility of the charge carriers in Midel 7131 and Diala D liquids are slightly different as compared with the values given in [37]. For negative energisation, the apparent mobility of the charge carriers in Midel 7131 is slightly higher than the previously reported value $\left(2.21 \times 10^{-3} \mathrm{~cm}^{2} \mathrm{~V}^{-1} \mathrm{~s}^{-1}\right)$. The apparent mobility of the charge carriers in Diala $\mathrm{D}$ oil is lower than the previously obtained value $\left(3.44 \times 10^{-3} \mathrm{~cm}^{2} \mathrm{~V}^{-1} \mathrm{~s}^{-1}\right)$, [37]. Rapeseed oil has the lowest value of apparent mobility of the tested liquids.

For positive energization, the apparent mobility of the charge carriers in Diala $\mathrm{D}$ has the highest value, $1.6 \times 10^{-3} \mathrm{~cm}^{2} \mathrm{~V}^{-1} \mathrm{~s}^{-1}$. The apparent charge mobility in the rapeseed oil is slightly lower than Diala $\mathrm{D}, 1.4 \times 10^{-3} \mathrm{~cm}^{2} \mathrm{~V}^{-1} \mathrm{~s}^{-1}$. The apparent mobility of the charge carriers in Midel 7131 is the lowest in this study. Different factors including pressure, temperature, and liquid kinematic parameters affect the apparent mobility of the charge carriers. It is known that the electric field induces electro-hydrodynamic (EHD) motion in the liquid, which also makes a contribution to the apparent mobility. A simple evaluation of the EHD mobility can be done by equating the kinetic energy of the moving liquid to the electrostatic energy in the liquid, [38], thus the EHD mobility is the square-root of the relative permittivity of the liquid divided by its density. The EHD motilities evaluated for the three liquids used in the present work are similar in value $\left(1.71 \times 10^{-3} \mathrm{~cm}^{2} \mathrm{~V}^{-1} \mathrm{~s}^{-1}\right.$ for Midel $7131,1.66 \times 10^{-3} \mathrm{~cm}^{2} \mathrm{~V}^{-1} \mathrm{~s}^{-1}$ for Diala D oil and $1.64 \times 10^{-3} \mathrm{~cm}^{2} \mathrm{~V}^{-1} \mathrm{~s}^{-1}$ for rapeseed oil) but lower than the measured negative apparent mobilities shown in Table 4. Therefore, other factors such as an increase in the liquid velocity in non-uniform fields contribute to the apparent mobilities obtained from the $\sqrt{ } I(V)$ curves, which are similar to the results obtained in [36].

Table 4. Coefficient $B$ and apparent mobility, $\mu$.

\begin{tabular}{c|c|c|c|c}
\hline \multirow{2}{*}{} & \multicolumn{2}{|c|}{ Negative } & \multicolumn{2}{c}{ Positive } \\
\cline { 2 - 5 } & $\mathrm{B}, \frac{n A^{1 / 2}}{\mathrm{kV}}$ & $\mu, \frac{c m^{2}}{V s}$ & $\mathrm{~B}, \frac{n A^{1 / 2}}{\mathrm{kV}}$ & $\mu, \frac{c m^{2}}{V s}$ \\
\hline Midel 7131 & 1.67 & 0.0025 & 1.15 & 0.0012 \\
\hline Diala D & 1.50 & 0.0029 & 1.12 & 0.0016 \\
\hline Rapeseed oil & 1.44 & 0.0021 & 1.16 & 0.0014 \\
\hline
\end{tabular}

The results presented in Figures 7-8 can be used for the identification of different conduction regimes in the insulating liquids. In low voltages (low electric field), the conduction can be characterised by the Ohmic current (resistive regime region). In this case, the electric field is governed by the Laplace equation and can be obtained using a standard electrostatic solver. With an increase in the applied voltage (higher electric field), the space charge saturation regime can be achieved. In this region, under high-voltage stress, the current reaches its space-charge saturation limit, [36], [37], which is described by Equations 1 and 2. In this case a standard electrostatic solver is inadequate and the Poisson equation should be used in order to obtain an accurate electric field distribution in the dielectric liquid. 


\section{CONCLUSIONS}

The ac breakdown voltages of Midel 7131 liquid, Diala D mineral oil and natural vegetable oil have been obtained using the ASTM D1816-04 standard test geometry and short interelectrode gap, $0.5 \mathrm{~mm}$. The fresh liquids used in the present study were tested "as received", and no special measures were taken in order to clean or remove water from these liquids.

Midel 7131 (synthetic ester) has a higher ac breakdown voltage as compared with Diala D mineral oil and rapeseed oil. The breakdown voltage of the Diala D oil has the smallest standard deviation (7\%) amongst the tested liquids (13\% for Midel 7131 and $11 \%$ for rapeseed oil). These results - the higher ac breakdown voltage of Midel 7131 than for the mineral oil, and the high standard deviation in the breakdown voltage for Midel 7131 than that for the mineral oil - are similar to the results obtained for degassed and dehydrated liquids in [11]. The breakdown ac electric field values obtained for the synthetic ester (Midel 7131) and mineral oil (Diala D) in the present study $(552 \mathrm{kV} / \mathrm{cm}$ and $496 \mathrm{kV} / \mathrm{cm}$ respectively) are slightly higher that the breakdown field values obtained in [11] for Midel $7131(470 \mathrm{kV} / \mathrm{cm})$ and the mineral oil, Nytro $10 \mathrm{GN}(390 \mathrm{kV} / \mathrm{cm})$. This can be explained by the shorter inter-electrode distance used in the present work $(0.5 \mathrm{~mm})$ as compared with $1 \mathrm{~mm}$ distance in [11]. It is known that the breakdown field is a non-linear function of the interelectrode gap, and higher breakdown field can be achieved in shorter gaps stressed with impulsive and ac voltages (this can potentially be explained by smaller number of impurities in shorter gaps). Previous work, [39], reports $E_{b r} \sim 1 / d^{0.25}$ dependency of the breakdown strength, $E_{b r}$, on the short, sub$\mathrm{mm}$, inter-electrode gap distance, $d$, for $n$-hexane stressed with impulsive voltage. Using this dependency, the breakdown field for the Midel 7131 obtained in the present paper for $0.5 \mathrm{~mm}$ can be extrapolated into $1 \mathrm{~mm}$ gap, and this extrapolated value of $464 \mathrm{kV} / \mathrm{cm}$ is very close to $470 \mathrm{kV} / \mathrm{cm}$ obtained in [11]. Another study, [40], shows that the breakdown voltage is a non-linear function of the distance for $50 \mathrm{~Hz}$ ac energisation, which means that the breakdown field decreases with an increase in the inter-electrode distance. It is shown in [15] that the breakdown voltage increases nonlinearly with the inter-electrode gap spacing for sub-mm distances.

The food-grade rapeseed oil (natural ester) used in the present work has the lowest average breakdown voltage and the standard deviation which is between those for synthetic ester and mineral oil, $24.8 \pm 2.7 \mathrm{kV}$. However, the breakdown voltage level is only $\sim 6 \%$ lower than the breakdown voltage of the mineral oil tested in the present work. The breakdown voltage of the rapeseed oil decreases with its relative humidity. The authors of [35] reported a $\sim 25 \%$ decrease in the ac breakdown voltage for rapeseed oil which was in contact with ambient air for 10 days as compared with dry rapeseed oil. The authors concluded that in order to use the rapeseed oil as industrial insulating fluid, this oil should be dried and isolated from air in order to minimise moisture uptake, [11]. Reference [41] shows that natural ester with a relative water content of
$50 \%$ has ac breakdown voltage more than two times lower that the dry ester liquid. The breakdown field values reported in [42], 214-226 kV/cm for dry oil and $169 \mathrm{kV} / \mathrm{cm}$ for oil which was in contact with ambient air, are relatively low. The same research group reported breakdown strength of $325 \mathrm{kV} / \mathrm{cm}$ for the rapeseed oil in [22]. The authors of [11] reported a higher breakdown field for the natural ester fluid, FR3 $(410 \mathrm{kV} / \mathrm{cm})$, than the breakdown field for the mineral oil, Nytro 10 GBN $(390 \mathrm{kV} / \mathrm{cm})$, which demonstrates that potentially, the breakdown voltage of the natural ester fluid can be as high the breakdown voltage of the synthetic ester (see also [20]). The breakdown field for the rapeseed oil found in the present paper is higher than those reported in [22] and [42], which can potentially be attributed (amongst other possible factors which are not considered here) to the shorter inter-electrode gap of $0.5 \mathrm{~mm}$ used in the present study, as compared with $2 \mathrm{~mm}$ in [22] and $2.5 \mathrm{~mm}$ in [42]. Again, assuming that the $E_{b r} \sim 1 / d^{0.25}$ dependency is valid, the extrapolation of the rapeseed oil breakdown field obtained in the present work for $0.5 \mathrm{~mm}$ gap $(496 \mathrm{kV} / \mathrm{cm})$ into $1 \mathrm{~mm}$ gap gives a value of $416 \mathrm{kV} / \mathrm{cm}$ which is very close to the breakdown field reported in [11] for the natural ester fluid, $410 \mathrm{kV} / \mathrm{cm}$. Reference [43] also demonstrates that the ac breakdown strength of insulating liquids including food-grade vegetable oil reduces substantially (by more than two times) with an increase in the gap from 0.3 to $3.0 \mathrm{~mm}$.

Statistical analyses of the obtained breakdown voltages show that these voltages can be described by the normal distribution for all three liquids. The actual breakdown voltages demonstrate noticeable deviation from the perfect normal distribution for voltages below $V_{10 \%}$ and for voltages above $V_{90 \%}$. These results can be important for design and management of the high-voltage systems.

$I-V$ characteristics for Midel 7131, Diala D and natural vegetable oil have been measured using both negative and positive high-voltage dc energisation. The electrode system used in these tests was a point-plane topology. The obtained $I$ $V$ characteristics were used to determine the apparent mobility of the charge carriers in these liquids. The apparent mobilities obtained in the present work for Midel 7131 and Diala D liquids are similar to the values reported in [37]. The apparent mobility of the charge carriers in the rapeseed oil is also similar to the mobility values of charges in the mineral oil and Midel 7131 ester fluid (the difference is up to $20 \%$ ). The $\sqrt{ } I(V)$ curves show that the space charge saturation regime is observed for all three liquids starting from $\sim 9 \mathrm{kV}$ for positive energisation and $\sim 10 \mathrm{kV}$ for negative energisation. These voltage levels indicate the threshold in the dc electric stress above which the Laplacian equation is not valid and the Poisson equation should be solved in order to obtain the accurate values of the electric field in the insulating liquids.

\section{REFERENCES}

[1] "Innovation funding incentive. Electricity transmission R\&D Program detailed reports", Annual Report, National Grid Plc, London, UK, 2011/2012. 
[2] V. M. Atrazhev, V. S. Vorob'ev, I. V. Timoshkin, M. J. Given and S. J. MacGregor, "Mechanisms of Impulse Breakdown in Liquid: The Role of Joule Heating and Formation of Gas Cavities", IEEE Trans. Plasma Sci., Vol. 38, pp. 2644 - 2651, 2010

[3] W. Choo, G. Chen and S. G. Swingler, "Electric field in polymeric cable due to space charge accumulation under DC and temperature gradient”, IEEE Trans. Dielectr. Electr. Insul., Vol. 18, pp. 596 606, 2011.

[4] U. Gafvert, A. Jaksts and G. Tornkvist, "Electrical Field Distribution in Transformer Oil", IEEE Trans. Electr. Insul., Vol. 27, No. 3, pp.647-660, 1992

[5] D. Martin, I. Khan, J. Dai and Z. D. Wang, "An Overview of the Suitability of Vegetable Oil Dielectrics for use in Large Power Transformers",The Annual Euro TechCon Conf, Chester, UK, pp. $1-20,2006$.

[6] MIDEL 7131 Power Transformer 135MVA/238kV, http://www.midel.com/library, accessed on 25 October 2013.

[7] P. Hopkinson, "Progress Report on Natural Ester for Distribution and Power Transformers", Panel discussion overview presented at the IEEE Power Eng.Soc. Transmission and Distribution Conf., USA, pp. 15-17, 2006.

[8] C. P Mcshane, J, Corkran, K. Rapp and J. Luksich, "Natural Ester Dielectric Fluid Development”, IEEE Power Eng. Soc. Transmission and Distribution Conf., pp. 18-22, 2006.

[9] S. D. Smith, "Design and Test Experience with Natural Ester Fluid for Power Transformers", IEEE Power Eng. Soc. Transmission and Distribution Conf., pp. 35-36. 2006.

[10] S. P. Moore, "Some Considerations for New and Retrofill Applications of Natural Ester Dielectric Fluids in Medium and Large Power Transformers", IEEE Power Eng. Soc. Transmission and Distribution Conf., pp. 25-29, 2006.

[11] D. Martin and Z. Wang, "Statistical analysis of the AC breakdown voltages of ester based transformer oils IEEE Trans. Dielectr. Electr. Insul., Vol. 15, No.4, pp.1044-1050, 2008.

[12] T. J. Gallagher; Simple Dielectric Liquids-Mobility, Conduction, and Breakdown, pp, 1-42, Oxford University Press, London, 1975.

[13] ASTM D1816-04, Standard test method for dielectric breakdown voltage of insulating oils of petroleum origin using VDE electrodes.

[14] K. C. Kao and J. B. Higham, "The Effects of Hydrostatic Pressure, Temperature, and Voltage Duration on the Electric Strengths of Hydrocarbon Liquids", J. Electrochemical Soc., pp.552-528, 1961.

[15] A. A. Zaky, R. Hawley, Conduction and Breakdown in Mineral Oils, Pergamon Press, Oxford, 1973.

[16] M. Butcher, A. Neuber, M. Cevallos, J. Dickens and H. Krompholz, "Conduction and breakdown mechanisms in transformer oil", IEEE Trans. Plasma Sci., Vol. 34, No.2, pp. 467$475,2006$.

[17] A. Nosseir, S. El-Debeiky,I. F. Hashad, H. A-Bary, "Effect of temperature on the breakdown probability of liquid dielectrics", IEEE Trans. Electr. Insul., Vol. EI-15, no.6, pp. 502-505, 1980.

[18] R. Diabi, J. C. Filippini, C. Marteau and R. Tobazeon, "On the role of temperature and impurities in the low field conduction of insulating liquids", IEEE 12th Int'l. Conf. Conduction Breakdown Dielectric Liquids (ICDL), pp 350 - 353, 1996.

[19] I. Fofana, H. Borsi and E. Gockenbach, "Moisture uptake of mineral oil at different air relative humidities and temperatures", IEEE Conf. Electr. Insul. Dielectr. Phenomena, pp.276-279, 2000.

[20] V.-H. Dang, A. Beroual and C. Perrier, "Comparative study of statistical breakdown in mineral, synthetic and natural ester oils under AC voltage", IEEE Int'l. Conf. Dielectr. Liquid, pp.1-4, 2011.

[21] J. M. Lehr, F. J. Agee, R. Copeland and W. D. Prather "Measurement of the Electric Breakdown Strength of Transformer Oil in the Sub-nanosecond Regime", IEEE IEEE Trans. Dielectr. Electr. Insul., Vol. 5, No. 6, pp.857-861, 1998.

[22] R. Badent, M. Hemmer and A. J. Schwab, "Inhibited rapeseed oil as substitute for mineral oils", IEEE Conf. Electr. Insul. Dielectr. Phenomena, pp. 268-271, 2002.

[23] M. P Wilson, I.V Timoshkin, M. J. Given, S. J. MacGregor, T. Wang, M. A. Sinclair, K. J. Thomas and J. M. Lehr, "Breakdown in mineral oil: Effect of electrode geometry and rate of Voltage
Rise", IEEE Trans. Dielectr. Electr. Insul., Vol. 19, No. 5, pp.1657-1664, 2012.

[24] I. L. Hosier, A. Guushaa, E. W. Westenbrink, C. Rogers, A. S. Vaughan and S. G. Swingler, "Aging of biodegradable oils and assessment of their suitability for high voltage applications", IEEE Trans. Dielectr. Electr. Insul., Vol. 18, pp.728-738, 2011.

[25] Y. Du, A. V. Mamishev, B. C. Lesieutre, M. Zhan and S. H. Kang, "Moisture solubility for differently conditioned transformer oils", IEEE Trans. Dielectr. Electr. Insul., Vol. 8, No.5, pp. 805$811,2001$.

[26] M. Koch, "Improved determination of moisture in oil-paperinsulations by specialised moisture equilibrium charts", XIV Int'1. Conf. High Voltage Eng., p.508, 2005.

[27] S. Tenbohlen, M. Koch, "Aging performance and moisture solubility of vegetable oils for power transformers", IEEE Trans. Power Delivery, Vol.25, No.2, pp. 825-830, 2010.

[28] M. Hemmer, Rapeseed Oil as Insulation and Cooling in Transformers", PhD thesis, University of Karlsruhe, Germany, 2004.

[29] I. Adamczewski, Ionization, Conductivity and Breakdown in Dielectirc Liquids, Taylor \& Francis Ltd, London, 1969

[30] D. Vukovic, S. Tenbohlen, J. Harthum, C. Perrier and H. Fink, "Breakdown strength of vegetable-based oils under ac and lightning impulse voltages", IEEE Int'l. Conf. Dielectric Liquids, pp.1-4, 2011

[31] C. Hosticka "Dependence of Uniform/Nonuniform Field Transformer Oil Breakdown on Oil Composition" IEEE Trans. Electrical Insulation, Vol. 14, No, 1, pp. 43-50, 1979.

[32] V. Segal, A. Hjortsberg, A. Rabinovich, D. Nattrass and K. Raj, "AC $(60 \mathrm{~Hz})$ and impulse breakdown strength of a colloidal fluid based on transformer oil and magnetite nanoparticles", IEEE Int'l. Sympos.Electr. Insul., pp. 619-622, 1998.

[33] G. Hwang, Markus Zahn, F. O'Sullivan, L. Pettersson, O. Hjortstam and R. Liu "Effects of nanoparticle charging on streamer development in transformer oil-based nanofluids", J. Appl. Phys., Vol. 107, pp.014310-1-17, 2010.

[34] M. J. Given, M. P. Wilson, P McGlone, I. V. Timoshkin, T. Wang and S. J. MacGregor, "The Influence of Magnetite Nano Particles on the Behaviour of Insulating Oils for Pulse Power Applications", IEEE Conf. Electr. Insul. Dielectr. Phenomena, pp. 40-43, 2011.

[35] G. Tinh, C. Vincent and J. Regis, "Statistical dielectric degradation of large volume oil-insulation", IEEE Trans. Power App. Syst., Vol. 101, pp. 3712-3721, 1982.

[36] M. Butcher, A. Neuber, M. Cevallos, J. Dickens and H. Krompholz, "Conduction and breakdown mechanisms in transformer oil", IEEE Trans. Plasma Sci., Vol. 34, No. 2, pp. 467475, 2006.

[37] I.V. Timoshkin, M. J. Given, R.A. Fouracre. S. J. MacGregor and J. M. Lehr, "Charge injection energy barriers and charge mobilities in insulating liquids", IEEE Conf. Electr. Insul. Dielectr. Phenomena, pp. 613-616, 2009.

[38] O. M. Stuetzer, "Magnetohydrodynamics and Electrohydrodynamics", Phys Fluids, Vol. 5, No. 5, pp.534-544, 1962.

[39] V. Y. Ushakov, V. F. Klimkin, S. M. Korobeynikov, Impulse Breakdown of Liquids, Springer-Verlag Berlin Heidelberg, 2007.

[40] http://cas.web.cern.ch/cas/Belgium2009/Lectures/PDFs/Tommasini.pdf, accessed 10 September 2013

[41] CIGRE Report 436 "Experiences in service with new insulating liquids", Working Group A2.35, 2010.

[42] R. Badent, K. Kist, B. Ruggemeier, W. Zierhut and A.J. Schwab, "Dielectric Characteristics of Rape-Seed Oil", IEEE Conf. Electr. Insul. Dielectr. Phenomena, Vol. 2, pp. 456-459, 1998.

[43] M. Marci and I. Kolcunova, "Electric breakdown strength measurement in liquid dielectrics", 9th Int'l. Conf. Environment and Electr. Eng., pp. 427 - 430, 2010.

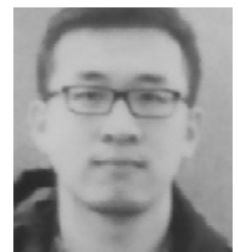

Yi Jing was born in Shanxi Provence, China in 1987. He received the B.Eng. and M.Sc. degrees in electronic and electrical engineering from the University of Strathclyde, Glasgow, UK, in 2010 and 2011 , respectively. He is presently studying for 
the $\mathrm{Ph}$.D. Degree at the University of Strathclyde, working on a project to analyze the dielectric properties of insulating liquids.

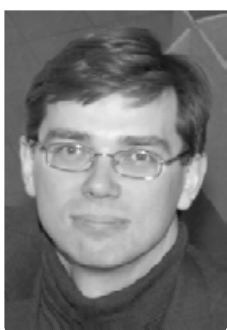

Igor V. Timoshkin (M’07) received a degree in physics from the Moscow State University (Russia) in 1992, and the Diploma and the Ph.D. degree from the Imperial College of Science, Technology and Medicine, (London, UK) in 2001. After graduation from MSU he worked as a Researcher at Moscow State Agro-Engineering University, and then at the Institute for High Temperatures of Russian Academy of Sciences before moving to ICSTM in 1997. He joined the University of Strathclyde (Glasgow, UK) in 2001, where he became a Senior Lecturer in 2011. His research interests include properties of solid and liquid dielectric materials, electronics of plasma discharges in condensed media, practical applications of electro-hydraulic and high-power ultrasound pulses, bio-dielectrics and effects of electromagnetic fields on biological objects.

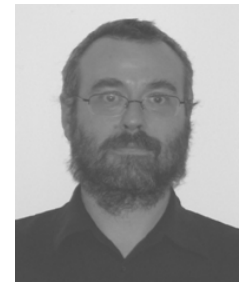

Martin J. Given (M’99) is currently a Senior Lecturer in the Department of Electronic and Electrical Engineering at the University of Strathclyde. He received the B.Sc. degree in physics from the University of Sussex in 1981 and the Ph.D. degree in electronic and electrical engineering from the University of Strathclyde in 1996. His research interests include, ageing processes and condition monitoring in solid and liquid insulation systems, high speed switching and pulse power applications

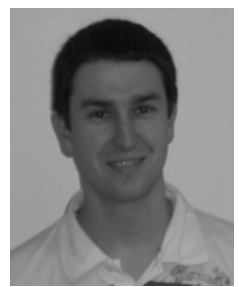

Mark P. Wilson (M'10) was born in Stranraer, Scotland, in 1982. He received the B.Eng. (with honours), M.Phil., and Ph.D. degrees in electronic and electrical engineering from the University of Strathclyde, Glasgow, U.K., in 2004, 2007, and 2011, respectively. He is presently working as a Teaching Associate at the University of Strathclyde, where he continues to investigate surface flashover of solids immersed in insulating oil. Mark is a member of the IEEE Nuclear and Plasma Sciences Society, from whom he received a Graduate Scholarship Award in 2011, the IEEE Dielectrics and Electrical Insulation Society, and the IET.
Scott J. MacGregor (M'95) received the B.Sc. and Ph.D. degrees from the University of Strathclyde, Glasgow, U.K., in 1982 and 1986, respectively. He

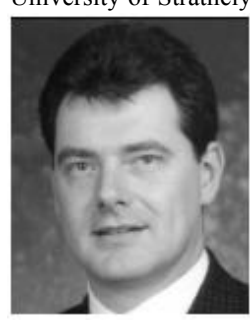
became a Pulsed Power Research Fellow in 1986 and a Lecturer in pulsed-power technology in 1989. In 1994, he became a Senior Lecturer, with a promotion to Reader and Professor of High Voltage Engineering, in 1999 and 2001, respectively. From January 2010 he became a Dean of Engineering Faculty of the University of Strathclyde. His research interests include high-voltage pulse generation, high-frequency diagnostics, high-power repetitive switching, high-speed switching, electronic methods for food pasteurization and sterilization, generation of high-power ultrasound (HPU), plasma channel drilling, pulsed-plasma cleaning of pipes, and stimulation of oil wells with HPU.

Tao Wang received the B.Eng and M.Sc. degrees from Northeast China

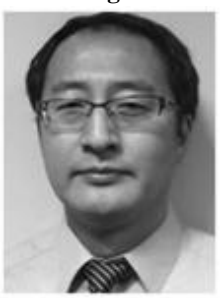
Dianli University (China) in 1993 and 1996, respectively, and the Ph.D. degree from the University of Strathclyde (Glasgow, UK) in 2005. He then joined the Newland Entech as a research fellow developing high efficiency industrial ozone generator. He joined the Department of Electronic and Electrical Engineering of University of Strathclyde as a lecturer in 2010. His research interests include non-thermal gas discharges and their applications in gas synthesis, water disinfection and advanced oxidation process in

water

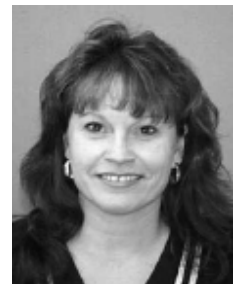

Jane Lehr (S'91-M'96-SM'02-F'08) received the B.Eng. degree from the Stevens Institute of Technology, Hoboken, NJ, and the Ph.D. degree in electro physics from Polytechnic University, New York, NY. Since 2002, she has been a Member of the Technical Staff with the Exploratory Pulsed Power Technologies Branch, Sandia National Laboratories, Albuquerque, NM, USA. Prior to joining Sandia National Laboratories, she was with the Directed Energy Directorate, Air Force Research Laboratory, USA. Dr. Lehr is a Past President of the IEEE Nuclear and Plasma Sciences Society. 